DEPARTMENT OF THE INTERIOR

UNITED STATES GEOLOGICAL SURVEY

\title{
HYDROGEOLOGY OF THE FORT UNION COAL REGION, EASTERN MONTANA
}

By Jefrey D. Stoner and Barney D. Lewis 